\title{
Diálogos entre Walter Benjamin e Glauber Rocha: uma leitura alegórica de Terra em Transe e o mito fundador do Brasil
}

\section{Dialogues between Walter Benjamin and Glauber Rocha: an allegorical reading of Terra em Transe}

\author{
Juliana Rocha Franco \\ Universidade Federal Rural do Semi-Árido, Mossoró, Rio Grande do Norte / Brasil \\ judorf@gmail.com
}

Resumo: Este trabalho tem como objetivo realizar uma leitura alegórica do filme Terra em transe (1967) de Glauber Rocha. Através de Terra em Transe buscaremos estabelecer um diálogo entre o filme e a obra de Walter Benjamin buscando compreender como Terra em Transe ultrapassa a crítica direta do populismo para empreender um diagnóstico mais geral do Brasil atravessando a História, sem se restringir à um período específico e dessa forma apresentar Terra em Transe como uma obra alegórica, uma metáfora encenada do próprio Brasil e suas circularidades. A alegoria possibilita apreender a expressão a um outro tempo subjacente às lutas do presente, num ciclo de repetição no qual o país sempre cai enquanto busca ser salvo. Depois da esperança, o golpe.

Palavras-chave: alegoria; Terra em Transe; democracia.

Abstract: This work aims to perform an allegorical reading of the movie Terra em Transe by Glauber Rocha. It will establish a dialogue between the film and the work of Walter Benjamin. The analysis seeks to understand how Terra em Transe surpasses the direct criticism of the populism to undertake a more general diagnosis of Brazil, going through History, without being restricted to a period accurate. This way, to present Terra em Transe as an allegorical work, a staged metaphor of Brazil itself and its circularities. Allegory makes it possible to grasp the expression at another time underlying the struggles of the present, arrested in a cycle of repetition in which the country always falls while seeking to be saved. After the hope, the coup.

Keywords: allegory; Terra em Transe; democracy. 
Recebido em: 18 de setembro de 2017.

Aprovado em: 6 de fevereiro de 2018.

\section{Introdução}

Etimologicamente falando, alegoria é o discurso por meio do outro (MOISÉS 1997, p. 14). A partir daí, pode ser derivada a ideia de uma historiografia alegórica. Ela se realiza no momento em que o estudo de uma outra época ou outra cultura é disposto de tal maneira que essa perspectiva proporciona ao historiador uma percepção mais aguda de sua época ou cultura., e vice-versa. A alegoria recusa noções como totalidade, progresso e continuidade, estimulando novas leituras da História. Conforme afirma Bolle (1994, p.108), a historiografia alegórica consiste na desmontagem de textos e na remontagem dos fragmentos com vistas a uma nova constelação textual.

Nas Teses Sobre o Conceito da História, Walter Benjamin (1994, p. 223) afirma que articular historicamente o passado não significa conhecêlo como ele de fato foi, significa apropriar-se de uma reminiscência, tal como ela relampeja num instante de perigo: o passado só pode ser compreendido quando é retirado da continuidade estabelecida pela história escrita pelos vencedores. A História só adquire significação nos momentos agudos, de crise. Para Bolle (1994, p. 40), essa é a essência do tratamento alegórico.

Benjamin propõe que a tarefa do historiador seja reconhecer o passado, arrancá-lo dos que ocultam e manipulam, e oferecê-lo aos dominados como uma experiência na qual eles se reconheçam. A partir do passado, deve-se reconstruir suas latências, recuperando as diferentes direções para onde ele apontava. A concepção benjaminiana da História é baseada na ideia de um tempo incompleto e inacabado uma forma de pensar que se opõe às visões míticas de uma história imutável, instaurada pelos vencedores para durar.

Concordamos com Starling (1999, p. 8), segundo a qual, um arcabouço historiográfico de natureza alegórica oferece algumas possibilidades e recursos metodológicos importantes, tais como construir uma história por meio de imagens (alegóricas, dialéticas, de pensamento etc.), superpor ou transpor épocas diferentes indicando sua condição de simultaneidade, além de possibilitar o estabelecimento de uma relação de 
correspondência entre o que Starling afirma ser duas partes extremas de linguagem: a ficção e a teoria, aproximando seus traços sem os confundir.

Trata-se de um processo de perceber a constelação formada pela sua própria época e uma determinada época anterior. Conforme afirma Rouanet (1997, p. 143), o historiador deve ser agudamente sensível ao apelo que vem do passado, para fixá-lo como uma imagem relampejante, reconhecendo-o como atual, como relevante para o presente. Assim, quando relaciona dois fatos distantes a alegoria (re)organiza a História em um movimento de atualização que torna próximo o que estava distante, convidando a novas leituras do passado. Conforme afirma Benjamin, o presente é iluminado pelo passado e o que foi reprimido pela história dominante emerge.

Para Willi Bolle (1994, p. 123) a alegoria é uma ação dramática congelada na imagem, metáfora encenada. Dentro desse contexto é possível afirmar que Terra em Transe é uma obra alegórica, uma metáfora encenada do próprio Brasil e suas circularidades, que se articula não tanto por conceitos, mas por meio de imagens que se repetem, em farsas sucessivas de uma "tradição perdida logo de início, como uma falha na origem como um gesto inconcluso de fundação" (STARLING, 1999, p. 39).

Benjamin (2006, p. 518) afirma que "escrever a história significa dar às datas a sua fisionomia". Segundo Bolle (1994), esse aforisma realça a importância da fisiognomia. Genericamente falando a fisiognomia benjaminiana é uma espécie de especulação das imagens, no sentido etimológico da palavra: um exame minucioso das imagens "prenhes de História" (BOLLE, 1994, p. 42).

A proposta do texto é estabelecer um diálogo entre o filme Terra em Transe e a obra de Walter Benjamin. Para Muller, A. (2017b, p. 34), "Glauber Rocha propunha, através de uma simbiose da poesia e do cinema, e de uma compreensão profunda da relação necessária entre tecnologia e arte, politizar a poesia e poetizar a política". Dessa forma é possível afirmar que o projeto alegórico de Glauber Rocha é semelhante ao de Benjamin, na medida que ele se dedica a mostrar personagens coletivos que circulam por sua obra. No filme, cada personagem condensa características que encarnam em uma unidade singular, segmentos da sociedade); e com os meios de um grande narrador (e aqui se estabelece outro ponto de diálogo entre o filme e Walter Benjamin, através do resgate da arte de narrar), apresenta as fantasias, os sonhos os devaneios de seus personagens, penetrando em seu fluxo de consciência, como se pode 
perceber na própria estrutura de flashback do filme, criando situações para uma possível redenção do passado.

A função do historiador para Benjamin, segundo Rouanet (1997, p. 113), não é extinguir a tradição em que os bens culturais são transmitidos de geração em geração, mas impedir que ela perca sua eficácia subversiva, ao ser remanejada pelos poderosos ou desapareça, condenando o homem à amnésia e inibindo a redenção do passado.

Ao recusar a continuidade histórica, a crítica Benjaminiana rejeita a ideia do progresso histórico. No contexto de crítica às ideologias do progresso é interessante trazer as observações de Benjamin (1994, p. 197-221) sobre o declínio da experiência no mundo moderno e do desaparecimento da arte de narrar.

O capitalismo altera o caráter das comunidades de trabalho ao instituir a divisão do trabalho e a especialização do trabalhador. A pulverização do trabalho se reproduz em todas as instâncias da vida social, e a base onde se instalavam a memória, a tradição comum que garantem a existência de uma experiência coletiva, se esvai.

As mudanças e a aceleração nas sociedades capitalistas modernas, geram um empobrecimento do trabalho e do passado coletivos, perde-se a capacidade de se intercambiar experiências, de narrar histórias (BENJAMIN, 1994, p. 197-221). Em tal contexto há uma perda da memória, através da qual as comunidades se relacionam com seu patrimônio cultural. No lugar da memória coletiva, a modernidade se apresenta a partir da fugacidade, velocidade e culto ao efêmero. Para Benjamim, esse processo destrói a memória bem como as faculdades mnemônicas.

Rouanet (1987, p. 113) aponta como essa degradação descreve o mesmo processo de fragmentação e secularização que Benjamin na mesma época analisou como perda da aura. Para o autor, o mundo pósaurático é da ordem da indiferenciada e da pobreza. Não assinala apenas o fim de uma experiência estética, mas o da experiência em geral. "O homem perdeu a capacidade de rememorar, típica da experiência e vegetaria na mera vivência" (ROUANET, 1987, p. 113)

Entretanto, reconhecimento dessa perda leva a busca de outras práticas que reconstruam, recriem uma experiência coletiva um universo incerto a partir de uma tradição esfaceladas. Um caminho proposto por Benjamin é a partir de experiências vividas isoladas (Erlebnis). É da Erlebnis que parte o esforço da memória, que em sua capacidade redentora resgata as correspondências entre o passado e o presente 
possibilitando a sua 'desalienação'. Isso poder visto em Proust. A cada esforço da memória o passado pode ser relido de forma diferente, havendo uma correspondência entre o relato do narrador tradicional e a reminiscência proustiana, possibilitando uma concepção do passado que não é unívoca: cada relato suscita novos relatos e a reminiscência leva a novas buscas. É dentro desse contexto que buscaremos compreender como Terra em Transe ultrapassa a crítica direta do populismo para empreender um diagnóstico mais geral do Brasil atravessando a História, sem se restringir à um período específico.

\section{Terra em transe e o resgate da Experiência}

Um longo plano de mar abre o filme Terra em Transe. As imagens levam o espectador do mar para a terra, e a trilha sonora é uma música de candomblé. O Título do filme aparece e em seguida, imagens que mostram um lugar identificado no final do plano como "Eldorado-País interior, atlântico". Os planos seguintes introduzem alguns personagens: O governador Vieira em seu palácio na província de Alecrim, ${ }^{1}$ aparece andando agitado, joga papéis no chão; é seguido por Sara e um assessor. Vieira chega ao terraço onde estão aliados, assessores, repórteres. O governador pede calma. A câmera passa a se deslocar de forma mais rápida e frenética em movimentos circulares. Corte para o carro de Paulo Martins em movimento. Paulo é um jornalista, intelectual apoiador do regime de Vieira (LOBO, 2016, p. 117)

Voltamos ao palácio e a agitação dos personagens parece ter diminuído um pouco, e o espectador é informado de que o presidente exige a renúncia de Vieira e acaba de enviar tropas militares para a província de alecrim para que isso se efetive. Paulo chega ao palácio do governador; a música de tambores é substituída por uma de cordas (que acentua a gravidade da situação) a câmera novamente retoma um movimento frenético e circular. Paulo joga nas mãos de Vieira uma metralhadora exigindo resistência ao golpe: "Agora temos que ir até o fim". O governador se recusa a resistir. Paulo e Vieira discutem. O movimento da câmera estabiliza e Vieira começa a ditar para Sara sua carta de renúncia.

A cena é cortada para o carro de Paulo que está acompanhado por Sara. Paulo ultrapassa uma barreira policial na estrada e é baleado por

\footnotetext{
${ }^{1}$ Caracteres na tela nos informam a localização do palácio.
} 
um policial. Ouvimos os tiros, no entanto não aparece nem sangue, nem vidros quebrados ou algum ferimento em Paulo ele continua dirigindo (ouvimos barulho dos pneus) e falando. Esse procedimento rompe com ilusionismo e o efeito de real no filme, indicando que mais importante que a verossimilhança é a transformação do seu discurso em um fluxo de consciência. Há um corte e o espectador vê Paulo nas dunas. Os versos de Mário faustino ${ }^{2}$ na tela enfatizam a morte de Paulo, que num estado entre a vida e a morte (um transe), inicia o esforço de rememoração que desencadeia o flashback em torno do qual se organiza o filme.

Existe no filme a mediação da subjetividade do poeta em toda narrativa: seu espírito contamina toda a narração embora não seja totalmente seu o relato. A representação dos fatos narrados proporcionados pelo filme, sejam eles narrados pelo personagem ou não, está contaminada pelo estado mental de Paulo, num ritmo fragmentado e irregular. Um bom exemplo é a sequência da renúncia de Vieira (apresentada por um narrador externo) e mostrada num registro que se relaciona profundamente com a maneira como o fato é experienciado por Paulo. A intensa mobilidade da câmera na mão reforça um a agitação nervosa e as atormentadas falas do personagem além da trilha sonora com ruídos e música acentuam a permanência da fragmentação e do transe.

No prólogo do filme o transe já aparece, prefigurado na música de candomblé, para depois se mostrar no comportamento dos personagens e no próprio ritmo dos acontecimentos influenciando a forma de narrar e abrindo possibilidade para possibilidades para várias leituras da obra. A narrativa imprime características delirantes ao país, às pessoas; tudo no filme se apresenta como num estado que não corresponde a normalidade.

Dentro deste contexto, parafraseando Starling (1999, p. 35), Paulo não descreve, narra. Uma narrativa descentrada parcial, fragmentada tecendo as imagens e palavras para reproduzir experiências com as hesitações, as impossibilidade e falhas de uma narrativa cheia de "agoras".

A narrativa se dá a partir da memória de Paulo, nesse caso, ele rememora, não o que ele viveu, "mas o tecido de sua rememoração, o trabalho de Penélope da reminiscência” (BENJAMIN, 1994, p. 37). Isso

2 "Não conseguiu firmar o nobre pacto

Entre o cosmo sangrento e a alma pura

(Tanta violência mas tanta ternura)" (Epitáfio de um poeta Mário Faustino) 
se dá quando a experiência de Paulo narrada, se cruza com o Paulo do presente que agoniza, desencadeando um processo de narração que se dá através do cruzamento desses dois registros temporais.

A imagem de Paulo nas dunas é acompanhada de uma voz over que é simultânea às letras do epitáfio na tela. Quando a voz over relata o passado, a utilização do pretérito separa o presente da voz que narra (o momento de agonia) do presente das ações evocadas. O passado é salvo quando é reconhecido, ao cruzar-se com um presente que lhe é sincrônico.

A memória de Paulo se projeta sobre os acontecimentos e seleciona momentos densos, agudos, de crise, tornando-o narrador da história, capaz de reconstruir o tempo da experiência. Na rememoração os fatos voltam a existir, saem da sucessão do tempo homogêneo e vazio. A memória capaz de recuperar a experiência desarranja a regularidade do tempo que nivela os acontecimentos numa sequência linear, criando uma história "Incompleta passível de transformações que admite vários desenvolvimentos possíveis, sequências imprevistas e conclusões desconhecidas ou até mesmo inventadas enquanto vai mantendo o interesse de quem ouve." (BENJAMIN, 2012, p. 230)

Ao ser capturada pela memória a tradição permite salvar o passado ao cruzá-lo com o presente. Para Benjamin a história é uma sucessão de "agoras", de experiências que são atualizadas pela memória. Dessa forma, os agoras de Paulo tornam-se experiência através do esforço de rememoração, que os faz saltar do continuum histórico, convertendo-os em um patrimônio social.

Segundo Arendt (2008, p. 28), todas as vezes que isso acontece e uma história irrompe em algum ser humano, o relato do ocorrido aí se detêm e acrescenta-se aos recursos do mundo. Retificada pelo poeta, pelo historiador ou pelo cineasta, a narração da história se integra à realidade dos homens obtendo permanência e estabilidade. A rigor, sua narrativa funciona quase como um esforço metodológico voltado para libertar o passado do historicismo e apreender a própria História na forma do fragmento. A memória de Paulo é capaz de conduzir o fio de uma narrativa que rompe com o critério de ordenação e seleção dos fatos do passado e subverte a autoridade da história.

Os contornos intensamente autobiográficos da vida de Paulo, lenta e deliberadamente fundidos aos materiais da memória coletiva e os traços de representação de épocas históricas, permitem um enfoque móvel que aproxima e distancia tempo e espaço até tornar legível um diagnóstico 
geral do país atravessando a História linear. Os personagens ganham uma figuração condensada, uma galeria de tipos e fatos que acaba por se referir a algo mais do que apenas a personagens da vida política dos anos 60, época do filme.

O prólogo de Terra em Transe nos apresenta a crítica situação de Eldorado: Porfírio Diaz, político conservador comandou um golpe de estado, suprimindo as aspirações políticas do líder populista Vieira. Ferido de morte ao empreender um ato isolado de resistência Paulo Martins revê sua trajetória política e a do país. Sozinho, nas dunas, o poeta inicia seu esforço de rememoração que originará o flashback em torno do qual a narrativa do filme é construída. Nas sequências finais do filme o circuito da memória de Paulo se completa e o espectador é reconduzido ao momento do golpe novamente.

O filme está pontilhado de repetições que reiteram a circularidade ${ }^{3}$ da narrativa; A maior e mais contundente delas é a repetição do prólogo do filme. Apesar de todo um desenrolar narrativo, a situação parece não evoluir, levando ao que Marilena Chauí (2005) denomina Mito fundador. A autora propõe compreender a ideia de Mito no sentido antropológico de solução imaginária para tensões, conflitos e contradições que não encontram caminhos para serem resolvidos no plano simbólico e muito menos no plano real (CHAUÍ, 2005, p. 5-6). Fundador, porque "impõe um vínculo interno com o passado como origem, com um passado que não cessa, que não permite o trabalho da diferença temporal e se conserva perenemente presente" (CHAUÍ, 2005, p. 6). Dessa forma o Mito fundador não cessaria de exprimir-se, em novos meios, de forma que, mesmo se expressando de formas diferentes, nada mais é que a repetição de si mesmo.

Chauí (1994, p.19-30) ainda afirma que existem quatro constituintes principais dessa matriz mítico-teocrática, elaborada no período da descoberta e conquista do Brasil. A seguir, apontaremos como o filme se desdobra nelas. O primeiro constituinte é uma produção mítica do Brasil enquanto o paraíso terrestre, que se constituiu no período das grandes navegações. E a chamada "visão do paraíso" (expressão tomada emprestada de Sérgio Buarque de Holanda). Em Terra em Transe isto é possível ser observado no nome Eldorado, que nos remete à lenda paradisíaca dos tempos de colonização. Essa produção mítica do jardim

\footnotetext{
${ }^{3}$ Como por exemplo na proliferação de faux raccords.
} 
do paraíso nos lançaria, como afirma Chauí (1994, p.19-30), "no reino da natureza, fora do mundo da história, no qual existe então apenas homens pacíficos e ordeiros a espera de um governante que o representará e manterá a harmonia originária".

O segundo elemento na produção do mito fundador é teológico, elaborada pela ortodoxia cristã (Agostiniana) a partir de uma perspectiva providencialista da História. Chauí (1994, p. 22-30) explica:

Com a vinda de Jesus, cumpriu-se a promessa de redenção. Como seres humanos mortais, estamos na eternidade participando da igreja, Jerusalém terrestre _e como humanos dotados de alma imortal participaremos da eternidade, o Reino de Deus como Jerusalém Celeste. O tempo é ocasião para o cumprimento do plano divino. (CHAUÍ, 1994, p. 22-30).

Assim, o Brasil como terra abençoada, paraíso reencontrado, e por isso está numa história que se realiza sem tempo e fora do tempo. Em Terra em Transe, não sabemos que tempo é, justamente por estar fora do tempo.

O terceiro elemento da elaboração mítica do Brasil é a história messiânica milenarista na qual emerge um elemento essencial: a figura do combatente que prepara o caminho de cristo. O pré-salvador, encarnado por um dirigente nas quais são todas as últimas esperanças: "Precisamos de um líder" com essa e outras afirmações Paulo Martins enfatiza a "necessidade" desse salvador no contexto político de Eldorado.

$\mathrm{O}$ quarto elemento componente da raiz mítica fundadora, de acordo com Chauí (1994, p. 27-28) encontra-se na elaboração jurídico teocêntrica do governante pela graça de Deus de a origem do poder humano é um favor divino àquele que "O representa". Dentro dessa estrutura, o governante não representa os governados, mas a fonte transcendente de poder e governar é realizar ou conceder favores. Tanto Diaz como Vieira encarnam esse papel de líder transcendente ao longo do filme.

Tal matriz mítica se conserva porque é periodicamente refeita com noções que correspondem ao seu presente histórico é a "História que se repete como farsa" como bem nos lembra Marx. Chauí (2005, p. 94) afirma que a mitologia é conservada através das ideologias que por sua vez encontram uma base material para se constituírem como 
expressões imaginárias da sociedade brasileira: o autoritarismo social, que se encontra, não somente na estrutura política institucional, mas esparramada em nosso tecido social, configurando "uma sociedade verticalizada e hierarquizada na qual as relações sociais são sempre realizadas ou pela forma da cumplicidade ou sob a forma do mando" (CHAUÍ, 1994, p. 27).

Dessa forma a igualdade direitos e a igualdade jurídica dos cidadãos não existe na prática. Segundo Chauí (1994, p. 28) a forma autoritária da relação é mascarada por aquilo mesmo que a realiza e conserva: relações de favor, tutela e clientela. Neste contexto, conforme afirma José Murilo de Carvalho (2001, p. 8) a relação do estado com o indivíduo é uma combinação de paternalismo e repressão, não gerando cidadania e criando no máximo estadania, a incorporação ao sistema político através da malha crescente da burocracia estatal.

Dentro desse contexto pode ser apontada a dificuldade de se realizar a ideia liberal da política democrática como um contrato (pois a condição primordial para que isso aconteça é a igualdade entre as partes) baseada nas ideias de cidadania e representação. Heynemann (2016, p. 30) sugere que "o transe, que abole as esferas do político e do privado: à análise do mito, que identificaria sua estrutura arcaica, teríamos em Glauber o mito arcaico referido ao estado das pulsões em uma sociedade atual".

\section{O eterno retorno do golpe no mito fundador:}

Em Terra em Transe, a progressão narrativa do filme insinua uma circularidade atada pelo que Ismail Xavier (2014, p. 60-61) denomina $O$ Emblema de Diaz. O emblema de Diaz mostra o ditador imóvel. Numa postura hierática em movimento (num carro que não aparece), segurando uma bandeira negra e um crucifixo.

Essa imagem aparece muitas vezes ao longo do filme e a cada inserção assinala um momento significativo (como por exemplo o início do flashback, na abertura da Biografia de um aventureiro etc). A imagem tem a força de um emblema porque através de poucos elementos expressivos sintetiza atributos essenciais do personagem. A representação da primeira missa ocorre logo após a primeira aparição do Emblema. Diaz está acompanhado por três figuras do período dos descobrimentos: um conquistador ibérico, um padre e um índio. Ele usa um terno do século XX, indicando uma estratégia alegórica: Diaz é o elemento 
arrancado de seu contexto original, o presente no passado, indicando que o autoritarismo contemporâneo remete ao autoritarismo colonial.

No filme esta estrutura autoritária também é mostrada na cerimônia de posse de Diaz que veste um terno do século XX e um manto real além de segurar um crucifixo; atrás dele uma figura vestida como um conquistador ibérico da era das descobertas segura a coroa por cima de sua cabeça. Em seguida temos um plano fechado de Fuentes com uma roupa de gala exibindo um sorriso vitorioso (com tons diabólicos).

Dessa imagem somos conduzidos à imagem de Diaz, Silvia e Fuentes ao subir os degraus da escadaria do palácio. A cena é cortada para um plano geral da cerimonia de coroação Diaz está rodeado de "súditos" vestidos como serviçais do Antigo regime. Representa o chefe de estado como um rei portador de emblemas de poder absoluto (coroa cetro e manto), cercado por um grupo de pessoas que evocam diferentes épocas da história do país. (o índio, o padre, o conquistador ibérico). Diaz coroado grita: "aprenderão, dominarei esta terra. Botarei estas histéricas tradições em ordem. Pela força, pelo amor da força, pela harmonia universal dos infernos, chegaremos a uma civilização".

É possível observar, através dessas sequências, os elementos do Mito fundador, tais como apontados por Chauí, no qual o autoritarismo social brasileiro leva a um ciclo de repetição de formas autoritárias de exercício de poder. Conforme afirma Muller (2017b, p. 34), "o fracasso do poeta de Terra em transe é a alegoria do fracasso de um país, que ainda não se encontrou."

$\mathrm{Na}$ circularidade da narrativa, o golpe de estado apresenta-se, portanto como repetição, e é o mesmo ato de dominação/domesticação/ repressão que definiu a ordem colonial, a hegemonia branca no encontro das culturas. A alegoria então dá expressão a um outro tempo subjacente as lutas do presente num ciclo de repetição no qual o país sempre cai enquanto busca ser salvo. Depois da esperança, o golpe.

\section{Considerações Finais}

Segundo Hayden White (1994, p. 98), uma das marcas do bom historiador é a firmeza com que ele lembra a seus leitores a natureza permanente provisória das suas caracterizações dos acontecimentos, dos agentes e das atividades encontradas no registro histórico sempre incompleto. Terra em Transe comporta várias leituras. Obviamente 
nenhuma delas dá conta de todo o potencial de significação do filme. Isto porque a alegoria é dialética: "Cada personagem, cada coisa, cada relação pode significar um outra qualquer" (BENJAMIN, 1986, p. 29)

Ao dizer o outro a alegoria permite que venha à tona o que foi reprimido pela história, trazendo as marcas da repressão. Como já afirmamos, a alegoria lida com as imagens de maneira descontínua, pressupondo a montagem e a inconclusão, solicitando do receptor uma disposição para análise. Sendo assim, para ser libertadora, a alegoria deve revelar-se polissêmica, deve remeter a vários outros, à vários significados, numa leitura que proponha interpretações que ultrapassem o mero nível convencional da linguagem alegórica, transcendendo o significado primeiro, para chegar ao significado subjacente foi o que procuramos fazer neste trabalho. Dentro deste contexto, indicação de uma única conclusão, de um único sentido marca um certo caráter autoritário. A leitura que não ultrapassa estes termos é uma leitura conservadora da alegoria porque é unívoca, relaciona apenas um significado a um significante desconsiderando as potencialidades transgressivas da alegoria. Por isso a conclusão de que este trabalho é um percurso em aberto, uma leitura dentre várias outras leituras que seriam possíveis de realizar do filme Terra em Transe.

\section{Referências}

ARENDT, Hannah. Homens em tempos sombrios. São Paulo: Editora Companhia das Letras, 2008.

BENJAMIN, Walter. Passagens. Belo Horizonte: Editora da UFMG; São Paulo: Imprensa Oficial do Estado de São Paulo, 2006.

BENJAMIN, Walter. Sobre alguns temas em Baudelaire. In: Charles Baudelaire - um lírico no auge do capitalismo. São Paulo: Brasiliense, 2000. (Obras escolhidas; v. III)

BENJAMIN, Walter. Obras escolhidas, v. I - Magia e técnica, arte e política: ensaios sobre literatura e história da cultura. São Paulo: Brasiliense, 1994.

BENJAMIN, Walter. Alegoria e drama barroco. In: . Documentos de cultura, documentos de barbárie: escritos escolhidos. Seleção e organização de Willi Bolle. São Paulo: Cultrix, 1986. 
BOLLE, Willi. Fisiognomia da metrópole moderna: representação da história em Walter Benjamin. São Paulo: Edusp, 1994.

CHAUÍ, M. Brasil: Mito fundador e sociedade autoritária. São Paulo: Editora Perseu Abramo, 2005.

CHAUÍ, Marilena. Raízes teológicas do populismo no Brasil: teocracia dos dominantes, messianismo dos dominados. In: DAGNINO, Evelina. Os anos 90: política e sociedade no Brasil. São Paulo: Brasiliense, 1994. p. 19-30.

CARVALHO, José Murilo de. Cidadania, estadania e apatia. Jornal do Brasil, 24 jun. 2001.p. 8.

HEYNEMANN, Liliane. Novo e Marginal: imagens de Glauber. DEVIRES - Cinema e Humanidades, v. 1, n. 1, p. 28-34, 2016.

LOBO, Júlio César. Precisa-se de um líder e de um poeta (Prática poética e prática militante no filme Terra em Transe, de Glauber Rocha. Especiaria: Cadernos de Ciências Humanas, v. 10, n. 17, 2016.

MATOS, Olgária CF. Os arcanos do inteiramente outro: a Escola de Frankfurt, a melancolia e a revolução. São Paulo: Brasiliense, 1989.

MOISÉS, Massaud. Dicionário de termos literários. São Paulo: Editora Cultrix, 1997.

MÜLLER, Adalberto. Muito além da adaptação: a poesia do cinema de Terra em transe. Revista Brasileira de Literatura Comparada, v. 10, n. 13, p. 115-140, 2017.

MULLER, Adalberto. A imagem poética: entre o material e o imaterial. Raído, v. 11, n. 28, p. 33-40, 2017 b.

ROUANET, Sérgio Paulo. As razões do iluminismo. São Paulo: Companhia das Letras, 1997.

STARLING, Heloisa Maria Murgel. Lembranças do Brasil: teoria política, história e ficção em Grande Sertão Veredas. Rio de Janeiro: Iuperj, 1999.

XAVIER, Ismail. Alegorias do subdesenvolvimento: cinema novo, tropicalismo e cinema marginal. São Paulo: Editora Cosac Naify, 2014.

WHITE, Hayden. Trópicos do discurso-ensaios sobre a crítica da cultura. São Paulo: Edusp, 1994. 